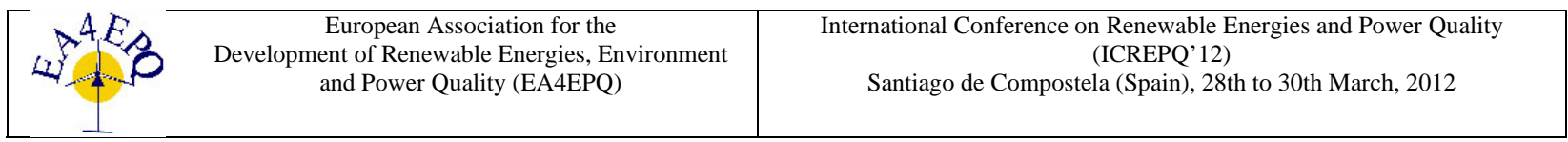

\title{
Design and Simulation of Supercapacitor Energy Storage System
}

\author{
M. Al-Ramadhan ${ }^{1}$ and M. A. Abido ${ }^{2}$ \\ ${ }^{1}$ Department of Electrical Engineering \\ King Fahd University of Petroleum and Minerals \\ e-mail: g200361410@kfupm.edu.sa, mabido@kfupm.edu.sa
}

\begin{abstract}
STATCOMs are widely used to enhance power system stability. They can exchange reactive power with the power system, but they have limited ability to exchange real power because they don't include energy storage devices. STATCOMs coupled with energy storage devices such as batteries have been introduced to improve their ability to exchange real power. However, batteries have a limitation in their maximum deliverable power because of the slow chemical process required to release their energy. The trend now is to use supercapacitor energy storage systems "SCESS" as energy storage for STATCOMS. Supercapacitors have lower energy storage but higher power exchanging capability compared to batteries. This paper presents the analysis, design, and control of a supercapacitor energy storage system (SCESS) for a STATCOM. A peak current mode controller is used to control the SCESS system. Simulation results of the SCESS system are presented which indicate excellent performance of the proposed SCESS system.
\end{abstract}

\section{Key words}

Supercapacitor, STATCOM, power system stability

\section{Introduction}

STATCOMs are widely used to enhance power system stability. STATCOMs by their own can exchange reactive power with the power system, but they have limited ability to exchange real power because they don't include energy storage devices. STATCOMs coupled with energy storage devices such as batteries have been introduced to improve their ability to exchange real power. However, batteries have a limitation in their maximum deliverable power because of the slow chemical process required to release their energy. The trend now is to use supercapacitor energy storage systems "SCESS" as energy storage for STATCOMs. Supercapacitors have lower energy storage but higher power exchanging capability compared to batteries.
The objective of this research is to design an SCESS system for a STATCOM. First, a literature survey is presented about the use of STATCOM-SCESS system to enhance power stability. Then, the detailed of the design of SCESS system and its controller are presented. Finally, a MATLAB/SIMILINK simulation model for the SCESS system is developed and the simulation results are presented.

\section{A. STATCOM}

Power system stability and power system quality can be enhanced by utilizing STATCOMs "Static synchronous compensators". STATCOM is one member of the FACTS "Flexible Alternating Current Transmission System" devices. It can exchange power with the power system. STATCOM can either be designed with or without an energy source. STATCOMs without energy sources mainly exchange reactive power with the power system, while STATCOMs with energy sources can exchange both reactive and real power [1].

\section{B. Supercapacitor energy storage system "SCESS"}

Supercapacitors were introduced since 1960's, but the interest has grown recently about utilizing them as an energy source for STATCOMs. Supercapacitors or ultracapacitors are electrochemical double layer capacitors with very high capacitance. Supercapacitors have very large surface area which makes their capacitance much higher than conventional capacitors. Their power rating is also much higher than a conventional battery because they can release energy quickly, while the chemical process in batteries makes them slower in releasing energy [2]. The SCESS system consists of the supercapacitor and the DC/DC converter that controls the flow of current from the supercapacitor [1]. 


\section{Literature Survey}

\section{A. Energy storage systems}

The authors in [2] describe many methods of energy storage for power system applications; namely, batteries, flywheels, supercapacitors, compressed air, hydraulic systems, and superconducting magnetic energy storage systems. Battery energy storage is used in many locations but its disadvantages are the limited discharge rate and the degradation with time. Hydraulic storage systems are also widely used but require large amount of land, and take long time to construct. Both supercapacitor and superconducting magnetic energy storages don't have those disadvantages, and they have fast response to electrical disturbances, and they can deliver high amount of power. The advantage of supercapacitor energy storage system over the superconducting magnetic energy storage system is that it does not need the cooling and the sophisticated structure which is required by the superconducting magnetic energy storage system [2].

The supercapacitors were known since 1960's. They are electrochemical double layer capacitors with very high capacitance. Supercapacitors are highly temperature and vibration resistive. They have a high discharge cycle, and they have the ability to provide or absorb high amount of power. Supercapacitor banks currently have a rated voltage up to $1.5 \mathrm{kV}$. The disadvantage of supercapacitor is that they store low amount of energy compared to batteries. Therefore, they are suitable for applications were high energy is needed for short time [2].

One major application for supercapacitors is electrical transportation systems. The authors in [3] propose a design of supercapacitor energy storage system for a Metro-vehicle. In this application, the kinetic energy is not completely wasted during breaking. Regenerative breaking was used to store the energy into a supercapacitor for later re-use. This method not only saves energy but also helps to stabilize the power system voltage. The authors in [4] also discuss how to select the size for a supercapacitor for a battery-supercapacitor hybrid system for the same application, and it mentions the advantages of this setup. The authors in [5] also proposed a novel control system for a hybrid electric vehicle which utilizes the supercapacitor energy storage system. The authors tested their system both through simulation using MATLAB/SIMULINK through hardware experiment through dSPACE control board.

\section{B. STATCOM-SCESS for improving power system stability}

Another application for the supercapacitor is improving power transmission and distribution system stability and quality. The authors in [6] proposed utilizing supercapacitor energy storage system for electronic power transformers. The proposed system can ride through momentary power interruption. Their system was tested using MATLAB/SIMULINK. The authors in [1] explored the use of supercapacitor with STATCOM, called STATCOM-SCESS system, to enhance power system stability and quality through simulation via Saber, and hardware experiment via dSpace board with a $9.5 \mathrm{~F}$ supercapacitor bank. They have shown how STATCOMSCESS system can improve power system stability against load variation.

The authors in [7] discussed using STATCOM with energy storage system for damping low frequency oscillations. The authors analyzed a generator-infinite bus system, and they developed a controller for the STATCOM with energy storage system to control the low frequency oscillations. Through digital simulation, the authors in [7] have shown that the STATCOM with energy storage system is more effective in damping low frequency oscillations than a power system without STATOM or a power system with STATCOM only.

\section{Design of supercapacitor energy storage system}

\section{A. Description of the power system}

The power system model used for the study is taken from [1]. It consists of one bus connected to the STATCOM, the load, and the main power supply as shown in (Figure 1). The bus is called the point of coming coupling (PCC). The model for the SCESS system consists of the supercapacitor, the DC/DC converter, and the dc link capacitor which is common between the SCESS and the STATCOM as shown in (Figure 2). The DC/DC converter is a bi-direction buck/boost converter which consists of two transistors for the buck and the boost action.

\section{B. Design of SCESS parameters}

The authors in [1] presented a detailed analysis of the SCESS system shown in (Figure 2) for selecting the system parameters. The fully charged and the end of discharge voltages for the supercapacitor were recommended to be $50 \%$ and $25 \%$ of the DC link voltage, respectively. The recommended value for the SCESS inductor is the one which minimizes the current ripple to $2 \%$ of the rated current, based on equation (1).

$$
\Delta I_{L}=\left(\frac{V_{S C}}{L}\right) d T .
$$

The authors in [1] recommended the value for dc link capacitor to be the one that minimizes the voltage ripple in the boost mode to $2 \%$, based on equation (2).

$$
\Delta V_{\text {dclink }}=\left(\frac{P d T}{C V_{d c l i n k}}\right) \text {. }
$$

The design for the SCESS elements is based on equation (1) and equation (2). The design requirements and the calculated parameters for the SCESS in this research are summarized in following tables (Tables I - IV). 


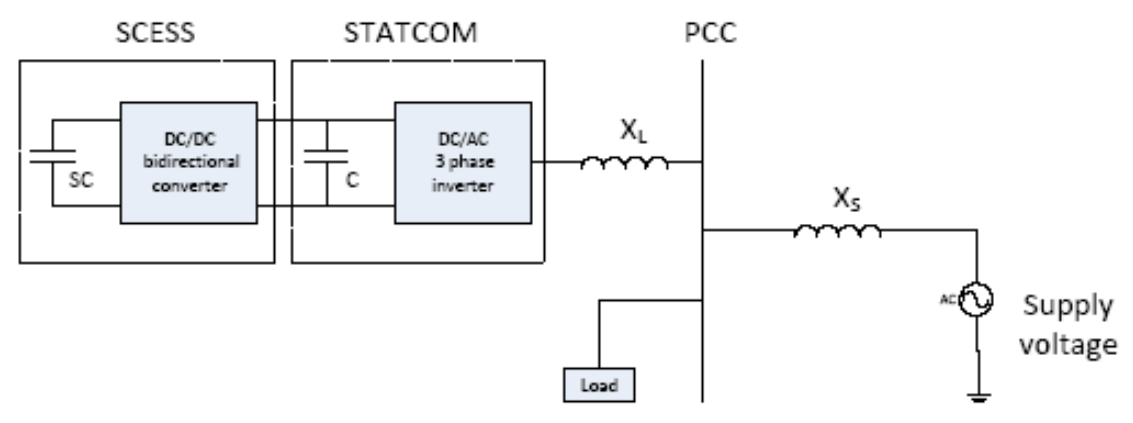

Fig. 1. Power system with STATCOM plus SCESS

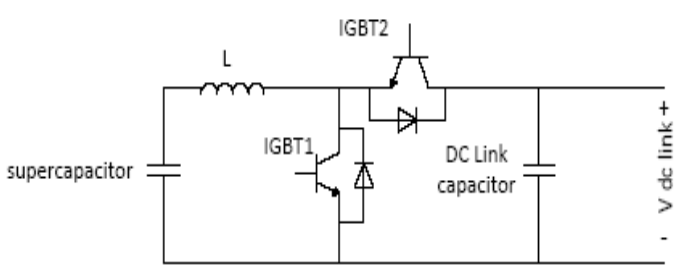

Fig. 2. SCESS circuit

Table I. - Current ripple calculations

\begin{tabular}{|c|c|}
\hline \multicolumn{2}{|c|}{ Current ripple calculations } \\
\hline rated power delivered by statcom (w) & 3000 \\
\hline rated DC link voltage (v) & 600 \\
\hline Rated dc link output current (A) & 5 \\
\hline Rated supercapacitor output current & 10 \\
\hline Required \% input current ripple & 0.02 \\
\hline Required input current ripple (A) & 0.2 \\
\hline
\end{tabular}

Table II. - Voltage ripple calculations

\begin{tabular}{|c|c|}
\hline \multicolumn{2}{|c|}{ Voltage ripple calculations } \\
\hline Rated power (w) & 3000 \\
\hline Switching period (s) & 0.0001 \\
\hline DC link Capacitance (uF) & 41.6667 \\
\hline Rated dc link voltage (V) & 600 \\
\hline Vripple (V) & 12 \\
\hline
\end{tabular}

Table III. - Supercapacitor calculations

\begin{tabular}{|c|c|}
\hline \multicolumn{2}{|c|}{ Supercapacitor calculation } \\
\hline rated dc link output power (w) & 3000 \\
\hline time of required power (s) & 120 \\
\hline Total energy required (J) & 360000 \\
\hline Super initial voltage (V) & 300 \\
\hline Supercapacitor end of discharge voltage (V) & 100 \\
\hline Supercapacitor capacitance (F) & 9 \\
\hline
\end{tabular}

Table III. - SCESS inductor calculations

\begin{tabular}{|c|c|}
\hline \multicolumn{2}{|c|}{ SCESS inductor calculations } \\
\hline Maximum boost duty cycle & 0.5 \\
\hline Maximum supercapacitor voltage (V) & 300 \\
\hline Switching period (s) & 0.0001 \\
\hline Maximum current ripple (A) & 0.2 \\
\hline SCESS inductance (H) & 0.075 \\
\hline
\end{tabular}

\section{STATCOM-SCESS controller}

The control system designed in this research for the SCESS is similar to the one used in [1]. The control system consists of two parts; namely boost mode control and buck mode control.

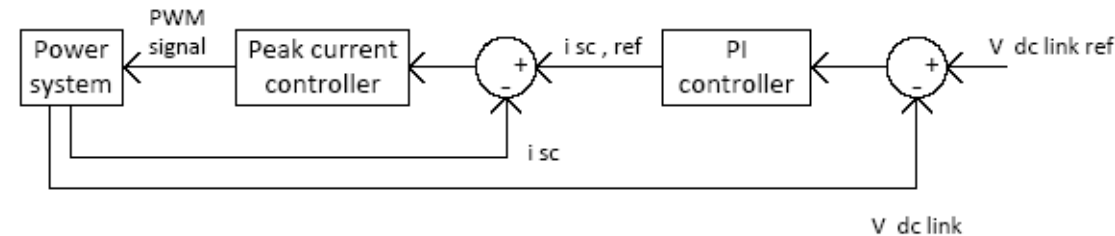

Fig. 3. SCESS boost mode control 


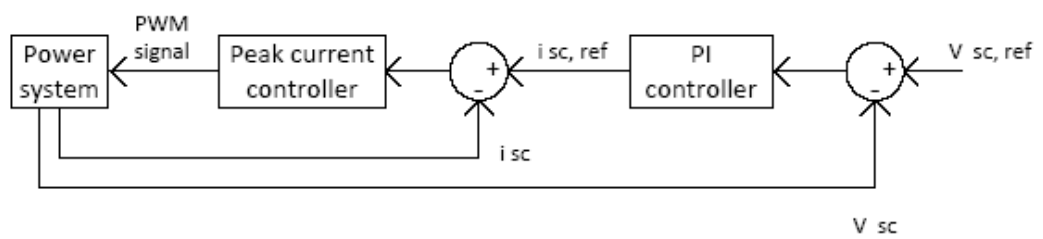

Fig. 4. SCESS buck mode control

In the SCESS boost mode control, the controller consists of one control loop which controls the discharge current inside another control loop that controls the DC link voltage. (Figure 3) shows the control block diagram for the SCESS in boost mode [1].

In the SCESS buck mode control, the controller consists of one control loop which controls the charging current inside another control loop that controls the Supercapacitor voltage. (Figure 4) shows the control block diagram for the SCESS in buck mode [1].

In both modes, the inner current loop current control is based on peak current control mode. The details of the peak current control mode are well explained in [8]. The outer voltage controllers are conventional PI controllers.

\section{Simulation of SCESS}

A MATLAB/SIMULINK simulation model was built for the SCESS system. It consists of the power circuit and the control circuit. The power circuit (Figure 5) consists of the supercapacitor, the inductor, the boost and buck IGBTs, the dc link capacitor, the dc load, and the switched on/off dc source. The DC load and the DC source represent a simplification of the STATCOM. The DC load is used to discharge the DC link capacitor while the DC source is used to charge it. The power circuit parameters are:

Supercapacitor: $\mathrm{C}=0.5 \mathrm{~F}$, and $\mathrm{V}(0)=300 \mathrm{~V}$. Inductor: $\mathrm{L}=0.075 \mathrm{H}$, and $\mathrm{R}=0.001 \mathrm{ohm}$.

DC link capacitor: $\mathrm{C}=800 \mathrm{uF}$, and $\mathrm{R}=0.01 \mathrm{ohm}$.

DC load: $\mathrm{R}_{\mathrm{L}}=120$ ohm.

DC source: $\mathrm{V}=610 \mathrm{~V}$, and $\mathrm{R}_{\mathrm{S}}=0.01 \mathrm{ohm}$.

The control circuit consists of one boost/buck logic circuit, which selects the mode of operation of the SCESS, two PI controllers, which are tuned with suitable proportional and integral gains to control the dc link and supercapacitor voltages, and two peak current controllers, which control the supercapacitor current in buck and boost modes.

The logic circuit (Figure 6) determines the mode of operation based on the following logic: If the dc link voltage is below $570 \mathrm{~V}$, the logic circuit will activate the boost mode until the dc link voltage is above $595 \mathrm{~V}$. If the supercapacitor voltage is below $300 \mathrm{~V}$, the logic circuit will activate the buck mode until the supercapacitor voltage is $315 \mathrm{~V}$, but the logic circuit does not allow starting the buck mode if the DC to DC converter is already in the boost mode.



Fig. 5. Supercapacitor, Boost transistor, Buck transistor and DC link simulation model in MATLAB 
The boost controller consists of two parts: the dc link voltage controller and the supercapacitor discharge current controller. The output of the controller is the PWM gating signal for the boost transistor. The dc link voltage controller (Figure 7) is a PI controller. The selected parameters are: Vref $=600 \mathrm{~V}, \mathrm{KP}=0.1$, and $\mathrm{KI}=1$. In addition, the output is subtracted by a small triangular signal which is important to eliminate small signal instability of the controller [8]. The output is the boost mode reference current signal. The supercapacitor charging peak current controller (Figure 8) compares measured current with the current reference signal, and the output of the comparator is connected to a flip-flop. The flip flop with the clock together have the function of producing the pulses for the IGBT. This scheme allows generating pulses with fixed frequency and variable width to achieve a current which approximates the reference current signal. The frequency of switching is determined by the clock frequency which is set to $10 \mathrm{kHz}$.

The buck controller is very similar to the boost controller. The difference is that it controls the Supercapacitor voltage instead of the dc link voltage. The selected parameters are: $\mathrm{Vsc}$,ref $=300 \mathrm{~V}, \mathrm{KP}=12, \mathrm{KI}=0.04$, clock frequency $=10$ $\mathrm{kHz}$.



Fig. 6. Buck boost logic circuit model in MATLAB

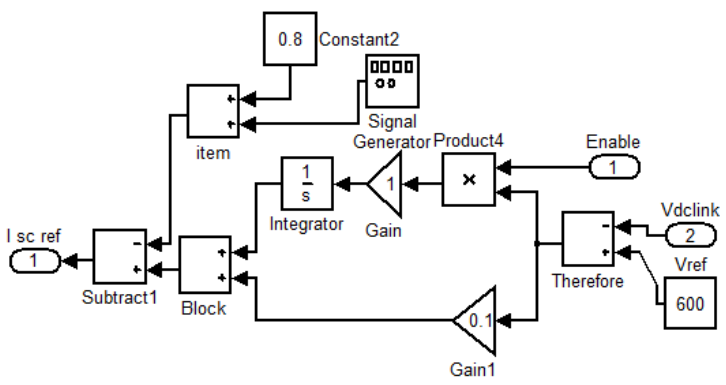

Fig. 7. DC link voltage controller model in MATLAB



Fig. 8. Boost controller model in MATLAB

\section{Simulation Results}

The SCESS system was tested by disconnecting the main DC source at the dc link for 1 second. The dc source is disconnected at $\mathrm{t}=0$ and reconnected at $\mathrm{t}=1 \mathrm{~s}$. While the DC source is disconnected, the dc link capacitor shall starts discharging its stored energy to the resistor. As a result, the supercapacitor shall provide its energy to the dc link to maintain the dc link voltage fixed. The energy discharged into the resistor represents the energy transferred STATCOM to the load at the AC side. The objective of test is to check if the SCESS system has the ability to maintain the dc link voltage fixed at the pre-set value. Therefore this test is an indication of the proposed SCESS capability.

The simulation was run first with without SCESS system, and then with the SCESS system. The DC link voltage profile while the SCESS system is not active is shown in (Figure 9). The dc link voltage dropped to zero after 0.4 seconds.

The dc link voltage profile during the test while the SCESS is active is shown in (Figure 10). The supercapacitor maintained the dc link voltage with an initial voltage dip to $86.7 \%$ of the rated value. This means the supercapacitor is delivering its energy to stabilize the dc link voltage. The supercapacitor voltage profile during the test is shown in (Figure 11). The supercapacitor voltage gradually decayed to $93 \%$ of the rated value. After the dc source is reconnected at $t=1 \mathrm{~s}$, the supercapacitor recharged to its initial value. The supercapacitor voltage reached the rated valued at $\mathrm{t}=1.2 \mathrm{~s}$. The boost mode SCESS system current ripple and dc link voltage ripple are also shown in (Figure 12) and (Figure 13), respectively.



Fig. 9. DC link voltage (V) versus time (seconds) without SCESS

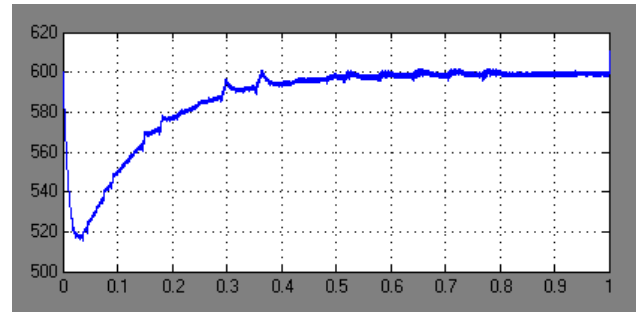

Fig. 10. DC link voltage (V) versus time (seconds) with SCESS 


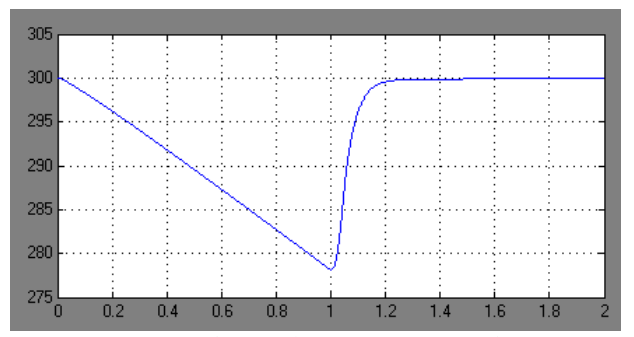

Fig. 11. Supercapacitor voltage (V) versus time (seconds)



Fig. 12. DC link voltage ripple (V) versus time (seconds) during SCESS boost mode

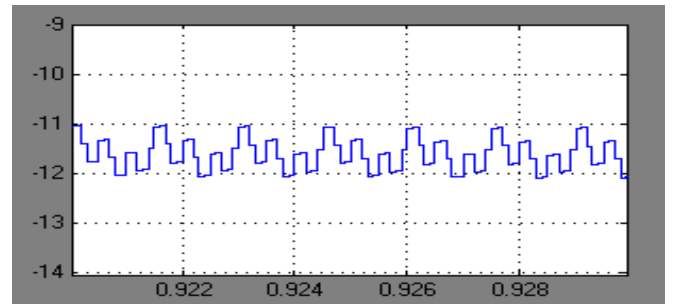

Fig. 13. Supercapacitor current ripple (A) versus time (seconds) during SCESS boost mode

\section{Conclusion}

STATCOM-SCESS is a promising technology for improving power system stability and quality. A brief literature survey was presented about the use of STATCOM-SCESS in various power system applications. The parameters and control schemes for the STATCOMSCESS were discussed. A simulation model was built and tested for the SCESS system on MATLAB/SIMULINK. The test shows that the SCESS system can maintain the dc link voltage by exchanging real power, which gives the STATCOM-SCESS the ability to exchange real power with the system.

This research can be extended by preparing a simulation model that includes both the SCESS and the STATCOM. It also can be extended by a hardware experiment of the proposed SCESS system.

\section{References}

[1] P. Srithorn, M. Sumner, and L. Yao, R. Parashar, "A STATCOM with supercapacitors for enhanced power system stability" $4^{\text {th }}$ IET Conference on Power Electronics, Machines and Drives , 2008 , pp.96-100.

[2] S. C. Smith, and P. K. Sen, B. Kroposki, "Advancement of energy storage devices and applications in electrical power system", IEEE Power and Energy Society General Meeting Conversion and Delivery of Electrical Energy in the 21st Century , 2008, pp.1-8.

[3] Z. Y-cheng; W. Lu-lu, Z. Xue-jun, and L. Hai-quan, "Design of Supercapacitor-based Energy Storage System for Metro
Vehicles and Its Control Rapid Implementation" IEEE Vehicle Power and Propulsion Conference, Harbin, 2008.

[4] N. S. Zhai, Y. Y. Yao, D. L. Zhang, and D. G. Xu, "Design and Optimization for a Supercapacitor application System", International Conference on Power System Technology, 2006.

[5] W. Lhomme, P. Delarue, P. Barrade, A. Bouscayrol, A. Rufer, " Design and Control of a Supercapacitor Design Storage System for Traction Applications", Industry applications conference, 2005.

[6] H. Liu, C. Mao, J. Lu, D. Wang, "Electronic power transformer with supercapacitors storage energy system", Electric Power Systems Research 79, 2009, PP. 1200-1208.

[7] K. Kobyashi, M. Goto, K. Wu, Y. Yokomizu, T. Matsumura, "Power System Stability Improvement by Energy Storage Type STATCOM" IEE Bologna Power Tech Conference, 2003.

[8] Kerin, Philip T., "Elements of Power Electronics," The Oxford series in Electrical and computer Engineering; Oxford university Press, (1998).

[9] C. Banos, M. Aten, P. Cartwright, T. C. Green, ; "Benefits and control of STATCOM with energy storage in wind power generation," the $8^{\text {th }}$ IEE International Conference on AC and DC Power Transmissions, 2006.

[10] C. Shauder, H. Mehta, "Vector analysis and control of advanced static VAR compensators." IEE Proceedings C, Vol. 140, No. 4, July 1993. 